Saudi Journal of Oral and Dental Research

Abbreviated Key Title: Saudi J Oral Dent Res ISSN 2518-1300 (Print) |ISSN 2518-1297 (Online) Scholars Middle East Publishers, Dubai, United Arab Emirates Journal homepage: http://scholarsmepub.com/sjodr/

Original Research Article

\title{
Perception of Orthodontic Treatment Needs
}

\author{
Shanthiprasad Indra B ${ }^{1^{*}}$, Anand K Patil ${ }^{2}$, Shrinivas Basavaraddy ${ }^{3}$, Niranjanaprasad Indra B ${ }^{4}$, Ganesh Chinthan ${ }^{5}$ \\ ${ }^{1}$ Senior Lecturer, Department of Orthodontics \& Dentofacial Orthopedics, Sharavathi Dental College \& Hospital, Shivamogga, India \\ ${ }^{2}$ Professor and Head of the Department, Department of Orthodontics \& Dentofacial Orthopedics, SDM College of Dental Sciences \& Hospital, \\ Dharawad, India \\ ${ }^{3}$ Professor, Department of Orthodontics \& Dentofacial Orthopedics, SDM College of Dental Sciences \& Hospital, Dharawad, India \\ ${ }^{4}$ Associate Professor, Department of Oral and Maxillofacial Surgery, Institute of Dental Sciences, Bareilly, Uttar Pradesh, India \\ ${ }^{5}$ Associate Professor, Department of Orthodontics \& Dentofacial Orthopedics, Sharavathi Dental College \& Hospital, Shivamogga, India
}

DOI: $10.36348 /$ sjodr.2019.v04i09.007

| Received: 06.09.2019 | Accepted: 24.09.2019 | Published: 30.09 .2019

*Corresponding author: Shanthiprasad Indra B

\section{Abstract}

Objective: To investigate the aesthetic perceptions of 100 consecutive patients and their parents of orthodontic treatment need and to compare their observations with that of orthodontists. Methods: The sample consisted of 100 consecutive orthodontic patients seen for the first time at Sharavathi dental college and Hospital. Of the total sample, 49 were males and 51 were females, with ages ranging from 7 to 21 years (mean + SD; $12.81+3.08)$. The self-assessment by patients and the recording by parents and orthodontists were carried out using the Aesthetic (AC) and Dental Health (DHC) Components of Index of Orthodontic Treatment Need (IOTN) as applicable. Results: The results showed a strong association in the perception of dental appearance by patients and the views of other dental assessors. These correlations were highly statistically significant $(\mathrm{P}<0.001)$ with the highest correlation between the parents and the orthodontists $(\mathrm{r}$ $=0.791$ ) while the least was between the patients and the orthodontists $(\mathrm{r}=0.653)$. The study also found that about onehalf of the patients were in the "definite need for orthodontic treatment". Conclusions: There is a strong relationship in the perceptions of dental appearance by patients, parents and orthodontists. This index could therefore be used as an effective tool in communication and achieving realistic treatment decisions.

Keywords: Orthodontic perception, Index of Orthodontic Treatment Need (IOTN).

Copyright @ 2019: This is an open-access article distributed under the terms of the Creative Commons Attribution license which permits unrestricted use, distribution, and reproduction in any medium for non-commercial use (NonCommercial, or CC-BY-NC) provided the original author and source are credited.

\section{INTRODUCTION}

In orthodontics, an understanding of how individuals perceive their occlusal features is essential need to ensure effective communication and to provide of adequate and necessary advice on treatment need. To establish a basis for realistic treatment decisions, it is important that the orthodontic problem is addressed in a way that is comprehensible to both the child and the parent.

Patients requesting orthodontic treatment do so primarily for aesthetic reasons although for the particular malocclusion, functional disability may also be significant. That means that the demand for correction of malocclusion is often based on psychological or psychosocial rather than on somatic factors [1-8]. Degree of perception of malocclusion has been found to be a better predictor of desire for treatment than the actual morphologic condition $[9,10]$.

Individuals' perception on aesthetics of dentofacial malrelationships often determines the perception of the need for and the desirability of orthodontic treatment. Whilst some patients are unaware of or relatively unconcerned about a pronounced malocclusion others may show a great concern over a relatively mild irregularity [11]. Several studies have revealed a discrepancy between an individual's own but personal views of the acceptability of his dental appearance and the views of dental assessors [12, 13]. Also some subjects neglect the severity of the irregularity 14 , others express dissatisfaction with objectively good occlusion $[4,9]$.

Experimental studies have also shown a discrepancy between lay and professionals with their judgements of dental aesthetics and need for treatment. According to Tedesco et al. [15] and Phillips et al. [16], persons with orthodontic training are less critical when rating aesthetic aspects of the teeth and face compared with those people without training. This is contrary to that reported by Prahl-Andersen et al. [17] who found that professionals are more critical with assessing and analyzing the acceptable range of facial profiles and 
dental irregularity than lay persons. Results of the study indicated a significant difference in only subjective evaluation of characteristics which is morphological in the dento-facial region between parents, dentists and orthodontists. The observed differences could be related to the differences within the three groups in their knowledge and experience in the subject.

Most of potential orthodontic patients are children or adolescents [18] and with their parents are therefore likely to play an important role in initiating treatment and supporting compliance. Studies have shown that the most powerful single factor in motivation for treatment is the parent [19-21].

This study was designed to investigate the aesthetic perceptions of one hundred consecutive patients and their parents of orthodontic treatment need and to compare their observations with the treatment need registered by orthodontists using the Index of Orthodontic Treatment Need (IOTN).

\section{METHODS}

The sample consisted of 100 consecutive patients seen first time at the Orthodontic department at SDC College and hospital, Shimoga between November
2014 and April 2017. Of the total sample, 48 were males and 52 were females, with ages ranging from 7 to 21 years (mean $\pm \mathrm{SD} ; 12.81 \pm 3.08$ ). None of the patients had received any form of orthodontic treatment. The assessment of the patients was done by the authors (B.S.P. AND A K G) who had been previously trained in using the Index of Orthodontic Treatment Need (IOTN) [22]. The Dental Health Component (DHC) of the index was based on various occlusal traits of malocclusion, with the most severe anomaly identified and recorded using the hierarchical scale of missing teeth (including congenital absence, ectopic and impacted teeth), overjets (including reverse overjets), crossbites, displacement of contact points and overbites .The DHC comprises of five grades which have been combined into three categories:

Grades 1 and 2 - No need for treatment

Grade 3 - Borderline need for treatment.

Grades 4 and 5 - Need for treatment". The Aesthetic component (AC) comprises of a scale of 10 anterior intra-oral photographs showing different levels of dental attractiveness (Figure 1): photographs 1-4 represent "No need for treatment"; 5-7, Borderline need for treatment" and 8-10 represent "Need for treatment".

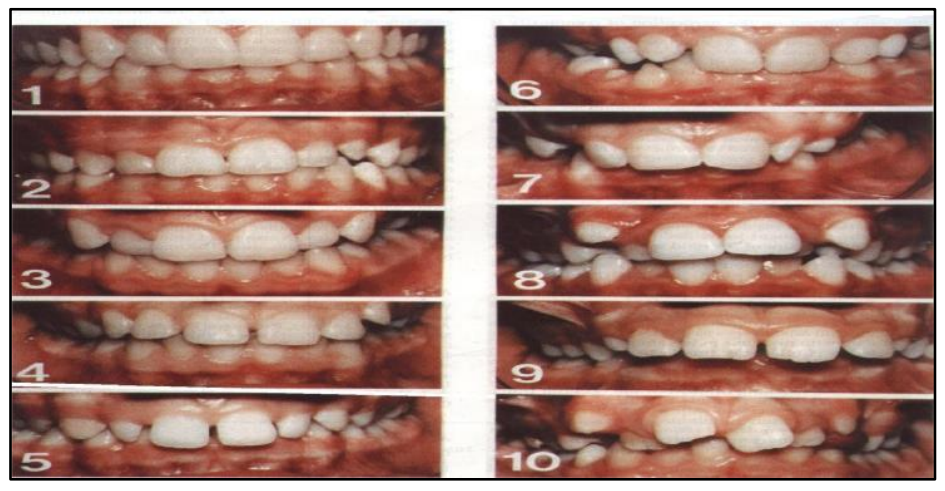

Fig-1: Aesthetic Component of Index of Orthodontic Treatment Need (IOTN)

The children were asked to match their overall dental appearance on the scale of 10 photographs in order to assess their perception of dental appearance. An independent assessment of the children's dental appearance by their parents was also carried out using the same photographs. The final assessment was done by the orthodontist using both the Aesthetic (AC) and Dental Health (DHC) components. A correlation coefficient test was used to compare the professional judgment of aesthetic need, the children's rating as well as their parents. A Chi-squared test was also used to assess differences in treatment need between genders. The software for the statistical analysis was the statistical programme of SPSS version 10 .

\section{RESULTS}

Figures 2 and 3 illustrate the gender distribution of $\mathrm{AC}$ scores recorded by the patients and parents respectively. The professional assessment using $\mathrm{AC}$ and DHC is shown in figures 4 and 5.

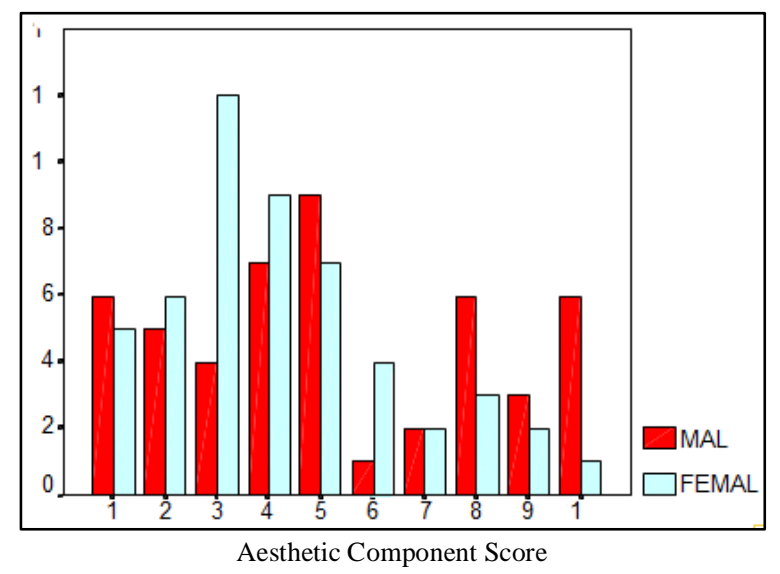

Fig-2: Gender distribution of aesthetic score recorded by the patients 


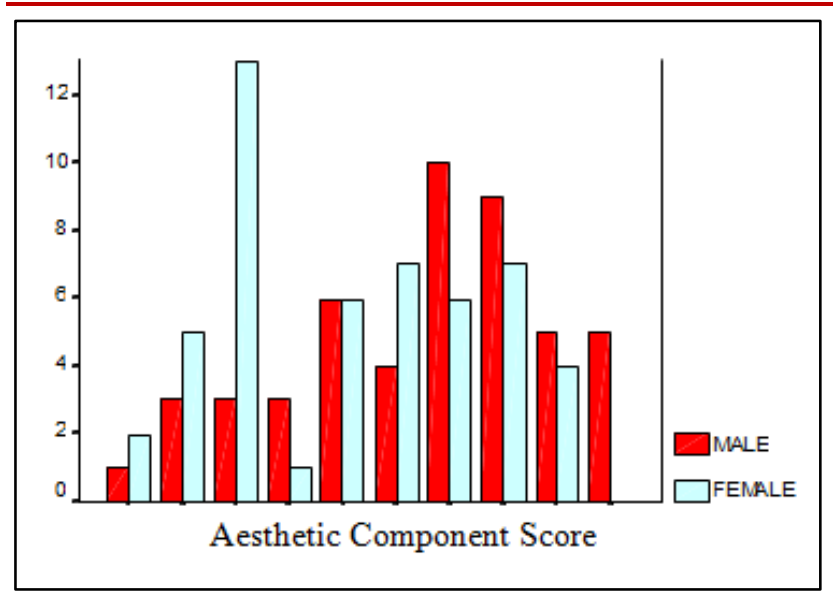

Fig-3: Gender distribution of aesthetic score recorded by the parents

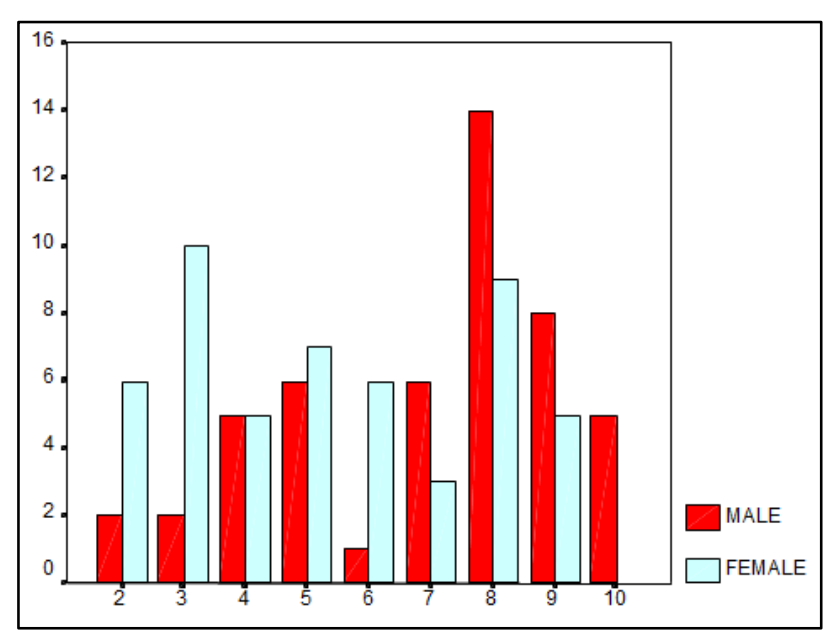

Fig-4: Gender distribution of aesthetic score recorded by Orthodontists

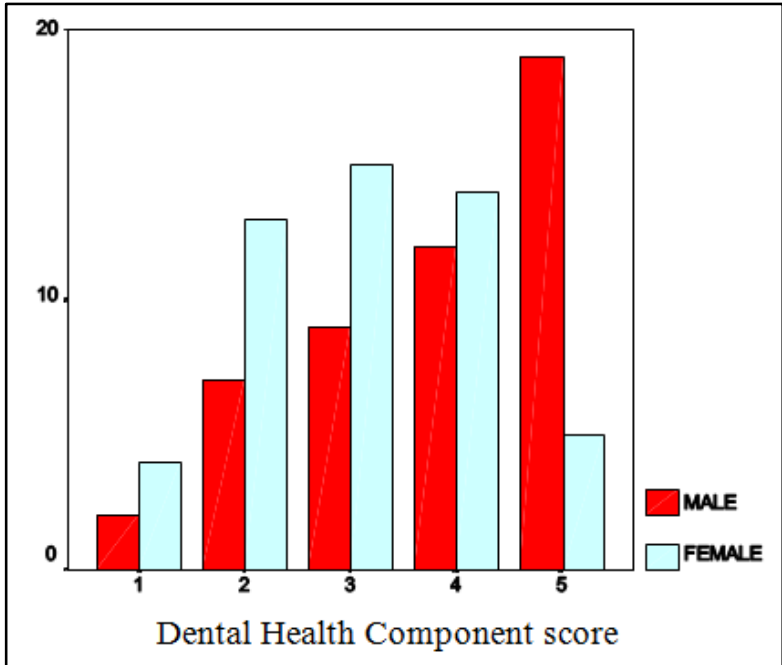

Fig-5: Gender distribution of dental health score recorded by Orthodontists

In all the ratings patients, parents and orthodontists using AC and DHC), there were a higher proportion of females than males at the attractive end of the scale. Unlike the orthodontist rating, the patients and parents ratings of dental appearance were generally found to fall within the more attractive range of the aesthetic scale. Generally, females were found to have more attractive dental appearance and less orthodontic treatment needs based on the professional judgment of $\mathrm{AC}$ and DHC However, there differences were not statistically significant $(\mathrm{P}>0.01)$. When categorizing the treatment of malocclusion according to urgency and need for treatment, most of the patients fell into "definite need of orthodontic treatment" ( $\mathrm{AC}=51 \%$; $\mathrm{DHC}=50 \%$ ).

There is a strong association in the perceptions of dental appearance by the patients, parents and the orthodontists (Table 3). These correlations were highly statistically significant $(\mathrm{P}<0.001)$ with the highest correlation between the parents and the orthodontists ( $r$ $=0.791$ ). Table 4 shows the cross-tabulation between the aesthetic and dental health scores based on the professional assessment. This was highly correlated $(\mathrm{r}=$ $0.698)$ and the association was highly Significant $(\mathrm{P}<0.001)$. (Tables 1 and 2$)$

Table-1: Treatment need of patients according to sex and aesthetic component (orthodontists' rating)

\begin{tabular}{|l|l|l|l|l|}
\hline AC & Treatment category & male & female & Total \\
\hline Grades 1-4 & No need/slight need for treatment & 9 & 21 & 30 \\
\hline Grades 5-7 & Moderate/borderline need for treatment & 13 & 16 & 29 \\
\hline Grades 8-10 & Definite need for orthodontic treatment & 27 & 24 & 51 \\
\hline
\end{tabular}

Gender differences $\mathrm{X} 2=4.03 ; \mathrm{df}=2 ; \mathrm{P}>0.01$

Table-2: Treatment need of patients according to sex and dental health component (Orthodontists' rating)

\begin{tabular}{|l|l|l|l|l|}
\hline DHC & Treatment category & male & Female & Total \\
\hline Grades 1 and 2 & No need/slight need for treatment & 9 & 17 & 26 \\
\hline Grade 3 & Moderate/borderline need for treatment & 9 & 15 & 24 \\
\hline Grades 4 and 5 & Definite need for orthodontic treatment & 31 & 19 & 50 \\
\hline
\end{tabular}

Gender differences $\mathrm{X}^{2}=6.80 ; \mathrm{df}=2 ; \mathrm{P}>0.01$ 
Table-3: Correlations* of aesthetic perceptions between patients, parents and orthodontists

\begin{tabular}{|l|l|l|l|}
\hline & Patients & Parents & Orthodontists \\
\hline Patients & 1.00 & 0.657 & 0.653 \\
\hline Parents & 0.657 & 1.00 & 0.791 \\
\hline Orthodontists & 0.653 & 0.791 & 1.00 \\
\hline \multicolumn{3}{|l|}{$* 00.001$ for all of the above correlations }
\end{tabular}

Table-4: Cross-tabulation of the orthodontists' $\mathrm{AC}$ and DHC scores

\begin{tabular}{|l|l|l|l|l|l|l|l|l|l|l|l|}
\hline \multicolumn{10}{|c|}{ AC score } \\
\hline DHC Score & 1 & 2 & 3 & 4 & 5 & 6 & 7 & 8 & 9 & 10 & Total \\
\hline 1 & - & 1 & 1 & - & 3 & 1 & - & - & - & - & 6 \\
\hline 2 & - & 6 & 4 & 3 & 3 & - & 2 & 2 & - & - & 20 \\
\hline 3 & - & 1 & 6 & 4 & 4 & 5 & 2 & 2 & - & - & 24 \\
\hline 4 & - & - & 1 & 2 & 3 & 1 & 4 & 11 & 4 & - & 26 \\
\hline 5 & - & - & - & 1 & - & - & 1 & 8 & 9 & 5 & 20 \\
\hline Total & - & 8 & 12 & 10 & 13 & 7 & 9 & 23 & 13 & 5 & 100 \\
\hline \multicolumn{8}{|c|}{ Correlation coefficient $\mathrm{r}=0.698 ; \mathrm{P}<0.01$} \\
\hline
\end{tabular}

\section{DISCUSSION}

The results of this study clearly indicate high agreement in perception of orthodontic treatment need as judged by patients and other dental assessors. Abreakdown of the aesthetic perceptions showed the highest correlation between parents and the orthodontists and the least between the patients and the orthodontists. The parents and the professional judgement are likely to be more objective than the patients' personal assessment. This is because patients tended to rate their dental appearance highly on the aesthetic scale compared with either their parents or the orthodontist. This observation was also reported by Myrberg et al. [13] in a group of 12-18 year-old rural Bangladeshi people. Furthermore, the orthodontist is likely to be more critical in the assessment of dental attractiveness because of the frequency with which he sees patients with extreme handicaps. His greater knowledge and experience with likely treatment outcome may also influence his assessment. This finding was supported by Shaw et al. [23] and Holmes [24] who reported that the dental aesthetic ratings of orthodontists were less favorable than those of the children.

It is important to note that malocclusion is not gender dependent as there were not statistically significant differences between male and female subjects. This is consistent with the literature on the swedish population $13,25,26$. Although it was not the intention of this study to assess the orthodontic treatment need in this population, but it is important to note that almost about one-half of the subjects were in the "definite need for orthodontic treatment". This is expected, as our population was a group of hospital referred patients who had varying degree of malocclusion and was seeking orthodontic treatment. This contrasts with the earlier cross sectional study that reported that about 62 per cent required no orthodontic treatment in a rural Indian population using the same
IOTN 13. Despite the criticisms leveled against the AC that it provides only two dimensional guides and insufficiently wide range of dental appearance, the aesthetic component of IOTN was highly comparable with the dental health component. The two can therefore be used independently to assess orthodontic treatment need.

\section{CONCLUSION}

In conclusion, there is a strong relationship in the perception of orthodontic treatment need as rated by patients and other dental assessors. The perceptions of dental appearance by patients and parents and professional judgment could be an effective tool in communication and achieving realistic treatment decisions.

\section{REFERENCES}

9. Espeland, L. V., Ivarsson, K., Stenvik, A., \& Alstad, T. A. (1992). Perception of malocclusion in 11-year-old children: a comparison between personal and parental awareness. The European Journal of Orthodontics, 14(5), 350-358.

10. Prahl-Andersen, B. (1978). The need for orthodontic treatment. The Angle Orthodontist, 48(1), 1-9.

11. Linn, E. L. (1966). Social meanings of dental appearance. Journal of Health and Human Behavior, 289-295.

12. Howitt, J. W., Stricker, G., \& Henderson, R. (1967). Eastman Esthetic Index. The New York state dental journal, 33(4), 215-220.

13. Jenny, J. (1975). A social perspective on need and demand for orthodontic treatment. International dental journal, 25(4), 248-256.

14. Shaw, W. C., Addy, M., \& Ray, C. (1980). Dental and social effects of malocclusion and effectiveness of orthodontic treatment: a review. Community Dentistry and Oral Epidemiology, 8(1), 36-45. 
15. Albino, J. E., Cunat, J. J., Fox, R. N., Lewis, E. A., Slakter, M. J., \& Tedesco, L. A. (1981). Variables discriminating individuals who seek orthodontic treatment. Journal of Dental Research,60(9), 1661-1667.

16. Otuyemi, O. D., \& Noar, J. H. (1996). A comparison between DAI and SCAN in estimating orthodontic treatment need. International dental journal, 46(1), 35-40.

17. Lewit, D. W., \& Virolainen, K. (1968). Conformity and independence in adolescents' motivation for orthodontic treatment. Child Development, 11891200 .

18. Gosney, M. B. (1986). An investigation into some of the factors influencing the desire for orthodontic treatment. British Journal of Orthodontics, 13(2), 87-94.

19. Shaw, W. C. (1981). Factors influencing the desire for orthodontic treatment. The European Journal of Orthodontics, 3(3), 151-162.

20. Otuyemi, O.D., Ugboko, VI., Adekoya-Sofowora, C.A.(1997). Orthodontic treatment need in rural Bangladeshi Adolescents. Community Dent Oral Epidemiol, 25:363-366.

21. Myrberg, N., \& Thilander, B. (1973). Orthodontic need of treatment of Swedish schoolchildren from objective and subjective aspects. European Journal of Oral Sciences, 81(2), 81-84.

22. Tedesco, L. A., Albino, J. E., Cunat, J. J., Green, L. J., Lewis, E. A., \& Slakter, M. J. (1983). A dentalfacial attractiveness scale: part I. Reliability and validity. American Journal of Orthodontics, 83(1), 38-43.

23. Phillips, C., Tulloch, C., \& Dann, C. (1992). Rating of facial attractiveness. Community dentistry and oral epidemiology, 20(4), 214-220.

24. Prahl-Andersen, B., Boersma, H., \& Moore, A. W. (1979). Perceptions of dentofacial morphology by laypersons, general dentists, and orthodontists. Journal of the American Dental Association (1939), 98(2), 209-212.

25. Haynes, S. (1991). Trends in the numbers of active and discontinued orthodontic treatments in the general dental service 1964-1986/87. British Journal of Orthodontics, 18(1), 9-14.

26. Phillips, C., Tulloch, C., \& Dann, C. (1992). Rating of facial attractiveness. Community dentistry and oral epidemiology, 20(4), 214-220.

27. Prahl-Andersen, B., Boersma, H., \& Moore, A. W. (1979). Perceptions of dentofacial morphology by laypersons, general dentists, and orthodontists. Journal of the American Dental Association (1939), 98(2), 209-212.

28. Haynes, S. (1991). Trends in the numbers of active and discontinued orthodontic treatments in the general dental service 1964-1986/87. British Journal of Orthodontics, 18(1), 9-14.

29. Otuyemi, O., Umweni, A., Dacosta, O., \& Fatusi, O. (2000). Attitudes and perceptions of Nigerian children towards orthodontic treatment. Pediatric dental journal: international journal of Japanese Society of Pediatric Dentistry, 10(1), 13-17.

30. Shaw, W. C., Gabe, M. J., \& Jones, B. M. (1979). The expectations of orthodontic patients in South Wales and St Louis, Missouri. British Journal of Orthodontics, 6(4), 203-205.

31. Pratelli, P., Gelbier, S., \& Gibbons, D. E. (1998). Parental perceptions and attitudes on orthodontic care. British Journal of Orthodontics, 25(1), 41-46.

32. Richmond, S., Burden, D., \& Buchaman, I. (1992). Basic introductory course in the use of occlusal indices. University Dental Hospital of Manchester, 3-15.

33. Shaw, W.C., Lewis, H.G., Robertson, N.R.E. (1975). Perception of malocclusion $\mathrm{Br}$ Dent J, 138: 211-216.

34. Holmes, A. (1992). The prevalence of orthodontic treatment need. British Journal of Orthodontics, 19(3), 177-182.

35. Phillips, C., Tulloch, C., \& Dann, C. (1992). Rating of facial attractiveness. Community dentistry and oral epidemiology, 20(4), 214-220.

36. Prahl-Andersen, B., Boersma, H., Van der Linden FPGM. (1979). Perceptions of dentofacial morphology by laypersons, general dentists, and orthodontists. J Am Dent Assoc, 98:209-212.

37. Haynes, S. (1991). Trends in the numbers of active and discontinued orthodontic treatments in the General Dental Service.19641986/87. Br J Orthod, 18: 9-14.

38. Otuyemi, O.D., Umweni, A., Dacosta. O. (2000). Attitudes and perception of Nigerian children towards orthodontic treatment. Ped Dent J, 10: 1317.

39. Shaw, W.C., Gabe, M.J., Jones, B.M. (1980).The expectation of orthodontic patients in South Wales and St Louis, Missouri. Br J Orthod, 7: 75-80.

40. Pratelli, P., Gelbier, S., Gibbons, D.E. (1998). Parental perceptions and attitudes on orthodontic care. Br J Orthod, 25: 41-46

41. Richmond, S., Burden, D., Buchaman, I. (1992). Basic introductory course in the use of occlusal indices. University Dental Hospital of Manchester, 3-15.

42. Shaw, W.C., Lewis, H.G., Robertson. N.R.E. (1975). Perception of malocclusion Br Dent J, 138 : 211-216.

43. Holmes, A. (1992). The prevalence of orthodontic treatment need. British Journal of Orthodontics, 19(3), 177-182. 